\title{
Undercutless caving at Newcrest: towards the next generation of cave mining
}

\author{
P Paredes Newcrest Mining Limited, Australia \\ IL Popa Newcrest Mining Limited, Australia \\ PR Kline Newcrest Mining Limited, Australia \\ MJ Sykes Newcrest Mining Limited, Australia
}

\begin{abstract}
Mass mining and particularly the cave mining industry is facing technical challenges that include those associated with greater depths, lower grades and demand for increased productivity (Flores 2014). New orebodies and expansion of current mines demand safer, faster, and lower-costapproaches to establishment and operation. The rate at which a cave is established is crucially dependent on the efficiency of the undercut process, which is becoming increasingly difficult and costly to execute in deeper orebodies. For these reasons, the development of alternative and more effective cave establishment methodologies has become critical. In this context, Newcrest has initiated the NextGen Caving programme, which endeavours to develop and implement novel, cost effective techniques for mining the next generation of block caves aiming to unlock low grade massive ore bodies at greater depths. Among the NextGen initiatives is the Undercutless Caving concept or Single Pass Cave Establishment (SPCE). This aims to improve safety, and reduce cave establishment time and cost, by establishing the drawbell and undercut components of a traditional block cave method from a single level and process. If proven to be successful, Single Pass Cave Establishment will not only change how Newcrest evaluates and constructs block cave projects, it will also represent a step change for the caving industry. To engineer, test, validate and implement this concept, Newcrest has embarked on an ambitious project consisting of a design study and two trials. This paper introduces the Undercutless Caving concept alongside the results of the first practical trial at the Telfer Mine in Western Australia. Successful results from a practical trial at Telfer have been achieved, with complete undercut and connectivity gained across the major and minor apex pillars of the planned four drawbell layout, of comparable pillar sizes to that at Cadia East. As an industry first of achieving drawbell and undercut establishment from a single level with no void above and with unprecedented drawbell and pillar dimensions, this milestone represents a significant step forward in cave establishment for the industry.
\end{abstract}

\section{Introduction}

Cave mining methods, due to their low cost and high productivity have historically been the preferred underground solution to profitably mine large, low-grade deposits. However, the cave mining industry has entered a less certain environment where some of the traditional cave mining options are already showing not to be fully suitable to achieving the envisaged low cost and high productivity (Flores 2019). This environment includes deeper and blind deposits ${ }^{1}$ ( $1,400 \mathrm{~m}$ from surface), lower grade, harder and heterogeneous rock masses, and higher in-situ rock stress regimes.

It is well understood that the major drawback of the block caving method is the high upfront capital cost and long lead time required to establish name plate production rates. Total lateral development to establish a new cave including access can be as much as $150 \mathrm{~km}$ and take up to 7 years, with capital costs ranging in the order of US\$2B to US\$5B (Macquarie Research 2016). Establishment time and cost is exacerbated by increasingly complex orebodies at depth, including depth related issues such

Orebody that does not extend to the surface, overlain by waste 
as low grades, strength/stress ratios, material handling costs, heat, etc. For orebodies of the future to be extracted safely and economically, step changes in mining strategies, techniques and processes are required. Developing a new cave establishment method is one of the strategies that could improve the performance of new large caving projects.

Over the last 20 years Newcrest has developed unique capabilities within the caving industry to efficiently mine deep and low-grade deposits, transitioning from Sublevel Caving in Ridgeway and Telfer during the early 2000's and more recently to Block Caving at Ridgeway Deeps, Cadia East PC-1 and PC-2. (Dunstan \& Popa 2012; Manca \& Flores 2013; Dunstan 2016). During this period over 250,000 $\mathrm{m}^{2}$ of block cave footprint has been undercut in high stress environments (Sigma 1 over 60MPa), with unprecedented column heights (over 1,000m) while achieving benchmark undercut rates (over $6,000 \mathrm{~m}^{2} / \mathrm{month}$ ) and production rates (steady state over $1.0 \mathrm{t} / \mathrm{m}^{2} /$ day) (Manca \& Flores 2013; Cuello \& Newcombe 2018). With block caving as a mining method, Newcrest is safely, reliably and efficiently mining deep low-grade deposits. This has been achieved through;

- The use of rockmass engineering including intensive preconditioning (hydrofracturing and confined blasting techniques) and innovative practices in mine design and drill and blast, which have enabled cave reliability through improved caveability and fragmentation.

- The implementation of robust extraction level layouts with large pillars that withstand cave establishment/propagation stresses and steady state production (Manca \& Flores 2013; Cuello \& Newcombe 2018).

Whilst Newcrest has proven capabilities to efficiently mine deep and low-grade deposits, a new way of thinking is required to overcome the challenges that come with even deeper (>1,400 m), lower grade and complex deposits.

To build on its proven capability and with an understanding of the challenges posed by the block caves of tomorrow, Newcrest has embarked on an innovation journey through the Next Generation Caving Programme (NextGen Caving). This initiative aims to develop and implement the processes, technologies and systems that will enhance the block caving method to provide safer workplaces, more sustainable mining processes, and converting deeper and lower grade deposits into Tier 1 assets. The core components of Newcrest's NextGen suite are:

1. Single Pass Cave Establishment (SPCE, also known as Undercutless)

2. Intensive pre-conditioning,

3. NextGen cave process control

4. Autonomous production, and

5. Post cave leaching

This technical paper is solely focussed on the Single Pass Cave Establishment programme, in particular the design, results and conclusions of the first practical trial conducted at Newcrest's Telfer Underground Operation in Western Australia.

\section{$2 \quad$ Undercutless caving}

\subsection{The context - a summary of modern mechanised cave establishment}

Traditionally modern mechanised block caves are established from two levels: the undercut level whose function is to facilitate the creation of a void above the draw horizon to induce the caving process, and the draw horizon (extraction or production level) where the drawbells are opened and connected to the undercut level, allowing caved ore to be extracted from the drawpoints. In this context, undercutting is the process whereby a slice of the orebody (typically 5 to $20 \mathrm{~m}$ high) is mined using various drill \& 
blast (D\&B) techniques. Depending on the order in which undercutting is performed (prior to or after opening the drawbell), the undercutting methods are classified as: advanced undercut, pre-undercut and post undercut (Rojas et al. 2000; Barraza \& Crorkan 2000; Butcher 2000; Trueman et al. 2002; Flores 2014; Laubscher et al. 2017). In the advanced and pre-undercut environments, the broken material from undercut blasting is removed through the undercut level; while in post undercutting the fired material is loaded directly from the already established drawpoints on the extraction level (Figure 1).

The common factor among current undercutting methodologies, is the requirement for the development of the undercut level and in some cases the further addition of an undercut apex level. This requirement has time and cost implications. In this project it has been found that for an advanced undercut method including an apex level, the development of the undercut can be up to $45 \%$ of the total footprint development metres. Undercutting activities also require dedicated ventilation, services and in some cases materials handling systems, which further add to the cost and time. Furthermore, undercutting activities also take place in the abutment zone and expose people and equipment to high stress areas and risk from seismic responses to mining.

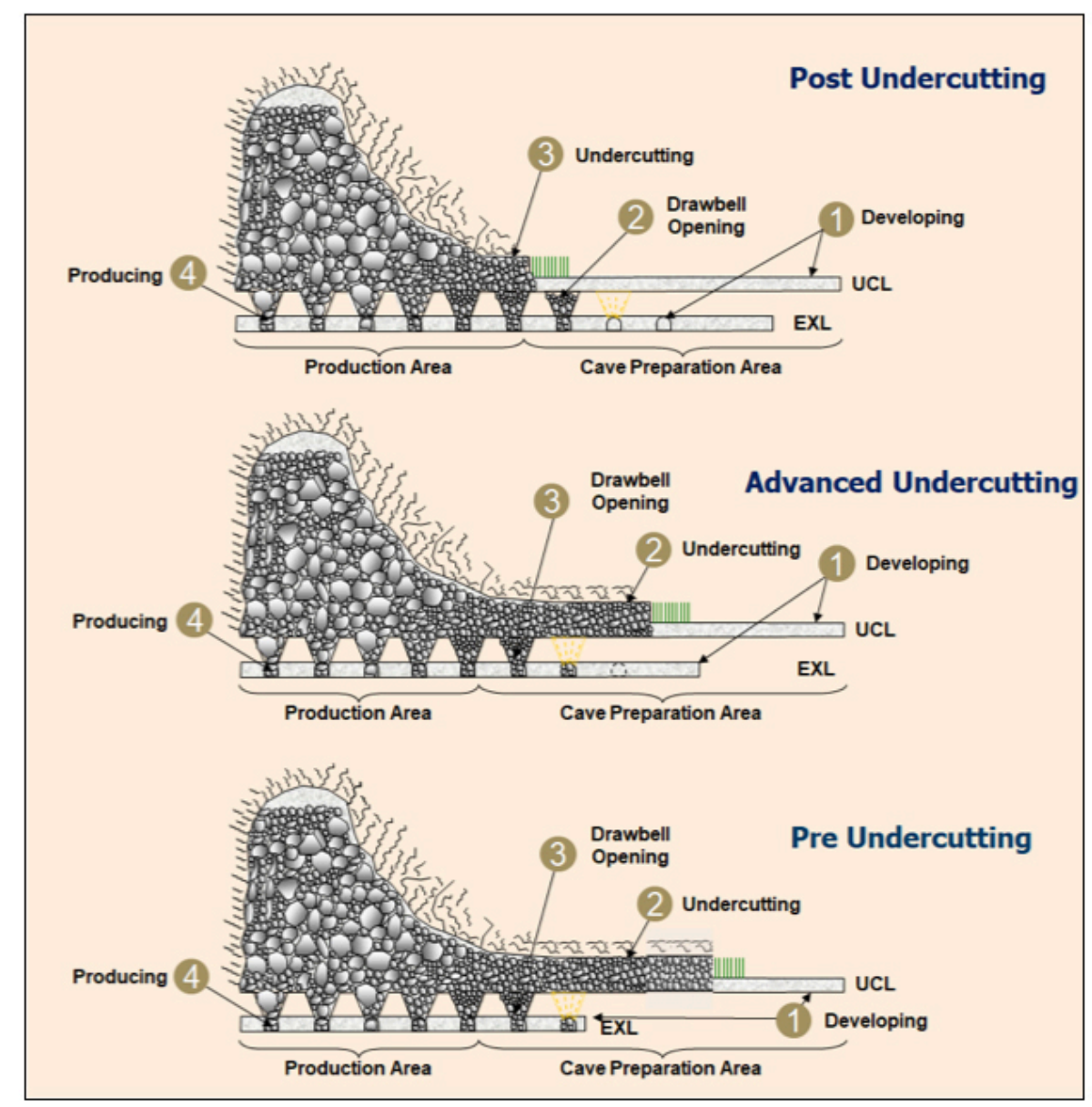

Figure 1 Conceptual cross sections of traditional undercut methods, depicting drawbell establishment sequence

\subsection{Undercutless cave establishment}

Undercutless cave establishment, or Single Pass Cave Establishment (SPCE), is an integrated drilling and blasting cave establishment method in which drawbell opening and undercutting are performed simultaneously from the extraction or production level, without the need for a dedicated undercut level (Figure 2). It is hypothesised that when compared with the conventional undercut methods, the SPCE method can: 
- Improve safety by removing the exposure of personnel to activities traditionally completed in the undercut level, which is typically a high stress area with risk of seismic response;

- Reduce cave establishment time;

- Reduce direct footprint capital cost;

- Be more amenable to automation and remote operation than traditional caving methods, as all processes are setup from a single level;

- Improve sustainability by reducing cost, thereby increasing deposit recovery.

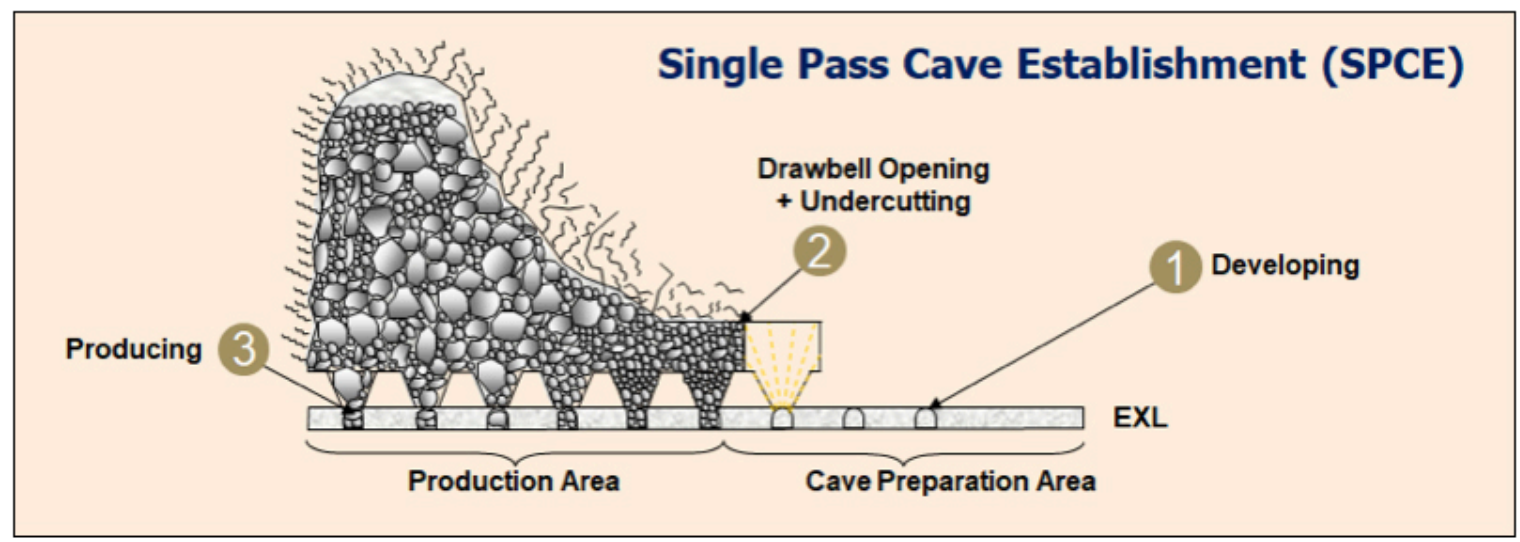

Figure 2 Conceptual cross section of SPCE

Conceptually, the main inherent risk of not having an undercut level is to not achieve a consistent undercut and drawbell connectivity, compromising the cave establishment. This is the main reason why a staged approach needs to be followed in order to engineer, test and implement a methodology that can reliably remove the undercut level.

\subsection{Undercutless establishment - industry experience}

To date, the published experience of the mining industry on undercutting from the extraction level is limited to El Teniente's "high drawbell" technique and the "no-undercut" tests carried out at Henderson Mine.

El Teniente mine in Chile used the "high drawbell" method to open drawbells from the extraction level such that they connect through the major and minor apex and undercut the orebody, without drilling and blasting from the pre-existing undercut level. The high drawbell method evolved as a contingency method to recover collapsed levels in 1991 and has since been used as a recovery alternative for areas with high geotechnical risks and collapse issues (Pierola et al. 2006; Codelco 2018; Vergara et al. 2018). This option has not been designed specifically as a primary undercutting method for new expansions, but as an adaptation of other methods to solve particular issues (Pierola et al. 2006; Tawadrous \& Preece 2015; Vergara et al. 2018).

The scope of the "no-undercut" trial conducted at Henderson Mine in 2013 was to develop a drill and blast method that could open the drawbell and achieve complete undercutting from the extraction level in a single blast event. The existing undercut drives above ensured connectivity between drawbells and, at the same time, offered the ideal observation point from which blast results could be assessed. Although the Henderson tests were considered successful, no further work was undertaken towards its implementation (Tawadrous \& Preece 2015; Climax Molybdenum 2018). 
Fundamentally, the El Teniente and Henderson methods (Figure 3a and Figure 3b) are alike in that both open the drawbells and undercut the orebody from the extraction level, and in both cases the existing undercut drives ensure complete connection between adjacent drawbells. However, there is no certainty that this method can be extensively applied in new orebodies or expansions of these without an existing undercut level. In addition, the established drawbell and pillar geometries at El Teniente and Henderson mines are significantly smaller when compared to Newcrest's geometries at Cadia East (see Figure 3 and Table 1).

The vision for the SPCE is to establish strong, long lasting drawbells and pillars that are required in deep caving environments, and which would match present Newcrest practice. To achieve comparable pillars to Cadia East, the SPCE requires increasing the heights and general dimensions beyond current industry experience in undercutless caving.

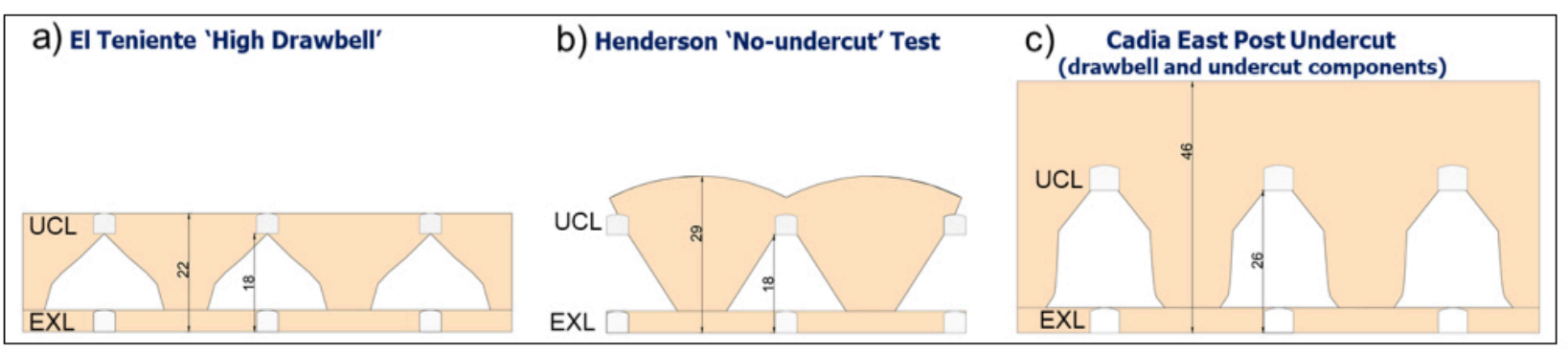

Figure 3 Conceptual sections perpendicular to the extraction drives, comparing: (a) El Teniente 'High Drawbell' concept (after Vergara et al. 2018); (b) Henderson 'no-undercut' test drawbells (after Tawadrous \& Preece 2015); (c) Cadia East Post Undercut (drawbell and undercut components)

Table 1 Comparison of key shape parameters: Newcrest's Drawbell and Undercut component to El Teniente 'High Drawbell' and Henderson 'no-undercut' test

\begin{tabular}{|c|c|c|c|c|}
\hline Concept & Unit & $\begin{array}{c}\text { El Teniente } \\
\text { 'high drawbell' }\end{array}$ & $\begin{array}{c}\text { Henderson } \\
\text { 'no-undercut' test }\end{array}$ & $\begin{array}{c}\text { Newcrest } \\
\text { post undercut }\end{array}$ \\
\hline Distance between levels (UCL and EXL) & $\mathrm{m}$ & 18 & 18 & 26 \\
\hline $\begin{array}{c}\text { Drawbell and undercut height (from EXL } \\
\text { floor) }\end{array}$ & $\mathrm{m}$ & 22 & 29 & 46 \\
\hline Distance between extraction drives & $\mathrm{m}$ & 30 & 31 & 32 \\
\hline Distance between drawbell drives & $\mathrm{m}$ & 20 & 17 & 20 \\
\hline
\end{tabular}

\section{$3 \quad$ Newcrest's path to single pass cave establishment}

Newcrest has planned cave establishment at Cadia East, Golpu and Red Chris, which represents a significant area of future block cave footprint to be undercut. The successful removal of the undercut level through the application of the SPCE method has the potential to bring significant benefit to Newcrest's portfolio, not only by improving the current project pipeline but also allowing potential improvement opportunities for current operations and future deposits. Furthermore, if proven to be successful, it is believed the SPCE method will not only change how Newcrest evaluates and develops block cave projects, it will also represent a significant step forward for the greater cave mining industry.

To realise the expected benefits derived from the elimination of the undercut level via the SPCE method, Newcrest has embarked on a technology development project consisting of a comparative study and two trials excavating full size drawbells, that is; full dimension drawbells of a limited number. The aspirational measures of success identified for the SPCE project are:

- Improve safety and reduced exposure of people to abutment stress present on the undercut level,

- Develop a robust and dependable cave establishment method, 
- Reduce direct cave footprint costs, and

- Reduce cave establishment time.

As stated previously, a staged approach needs to be followed in order to engineer, test and implement a methodology that can reliably remove the undercut level. Figure 4 outlines the roadmap from the study to potential implementation in the future Cadia East PC1-2, Red Chris and Golpu block caves. The project comparative study phase is intended to engineer and validate the safe and efficient large-scale implementation of the method as compared to current methods in parallel with full-scale trials of a select number of drawbells to be conducted at both Telfer and Cadia East. The trials aim to test and verify a proof of concept and an optimised version of the method, together with capturing the key data to model and assess the large-scale implementation within the study. The initial trial at Telfer was comprised of 4 drawbells and the intent was to test the first SPCE concept design using conventional technology and practices available on site. Further to this, the upcoming Cadia East trial will test an improved version of the design built upon learnings from the first trial which may include alternate drill and blast technologies. Importantly, neither trial is of sufficient area or hydraulic radius to induce major collapse or caving. The trials at Telfer and Cadia East aim to test the ability of the method to reliably generate the undercut shape and height and importantly connectivity across apices. Although the SPCE method will not be adopted in the upcoming PC2-3 block cave, at the completion of the Cadia East trial it is expected that final field test of the method sub-elements (i.e. drilling accuracy and productivity, explosive retention, detonator technology) to verify full deployment capability may be conducted at the back end of Cadia East PC23 block. Finally, pending full confirmation of the method's safety, efficiency and reliability, full scale implementation will be assessed for Cadia East's PC1-2, Red Chris and Golpu block caves.

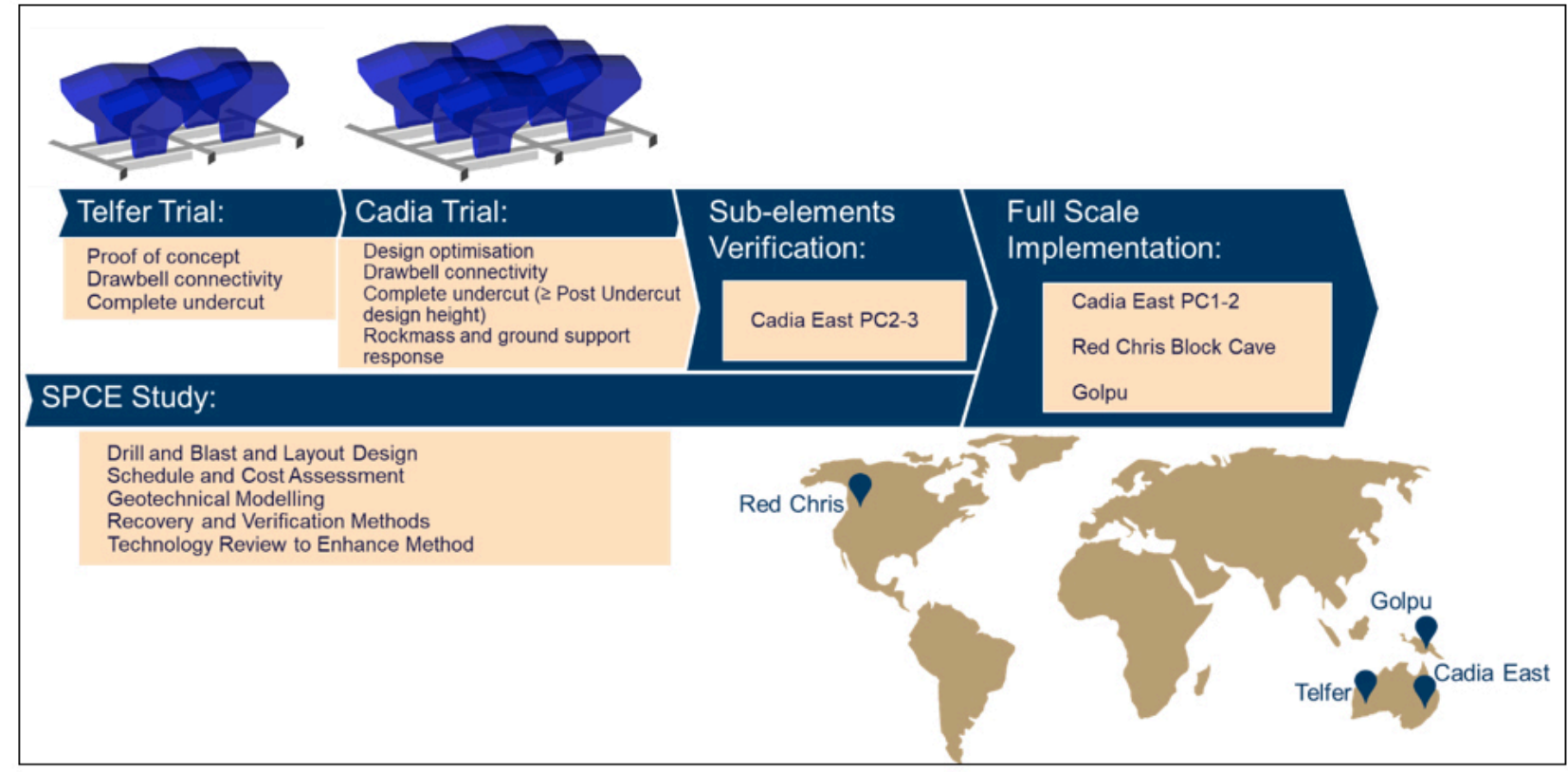

Figure 4 SPCE project roadmap to full scale implementation

\section{$4 \quad$ Telfer trial: first of its kind}

Commencing in January 2019, the Telfer trial was intended as a proof of concept of the SPCE methodology. Its scope consisted of four drawbells such that the ability to achieve a minimum height and to create connection - across the major and minor apices - could be validated. The key metrics of the trial were:

1. Safely execute the scope of four SPCE drawbells.

2. Establish functional drawbells and drawpoints and define strong pillars comparable in size to those of Cadia East.

3. Achieve the minimum height and complete undercut connectivity across the four drawbells. 
4. Minimise overbreak and pillar damage.

5. Identify roadblocks and improvement opportunities.

\subsection{Telfer mine overview}

The Telfer Gold Mine (Telfer), owned by Newcrest Mining Limited is located in the Great Sandy Desert approximately $400 \mathrm{~km}$ east-south-east of Port Hedland, and 1,300 km north-east of Perth (Figure 5a). Discovered in 1971 when anomalous gold and copper values were returned from outcrops in what is now known as Main Dome, surface and underground mining activities took place through the 1980's and 1990's. In early 2000 the operation was put into care and maintenance after producing approximately 6 Moz of gold. A feasibility study was undertaken in 2002 that established the strategy for bulk mining of lower grade material from the surface and underground deposits which led to the re-establishment of open pit mining operations in 2004 and underground operations in 2006 (Woods et al. 2019; Kilkenny et al. 2019)

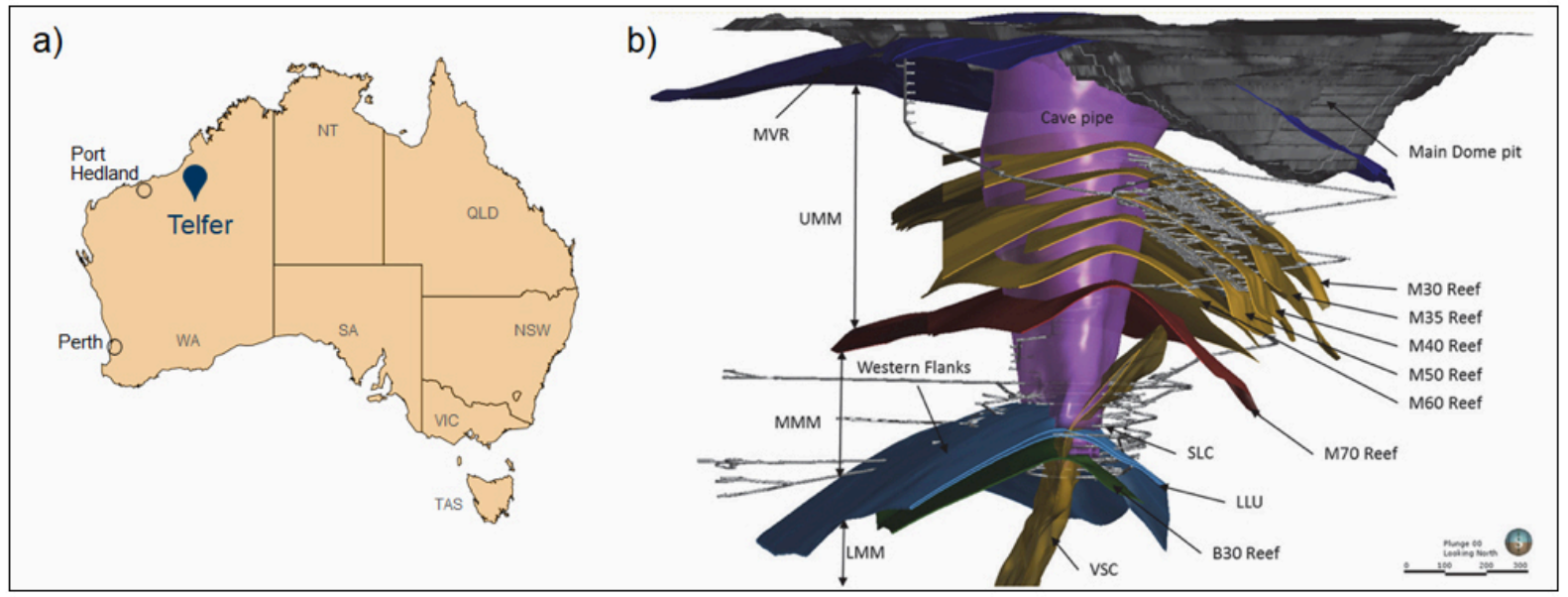

Figure 5 (a) Telfer mine location; (b) Telfer underground mine areas and geological units overview, looking north (after Woods et al. 2019)

The underground mine is emplaced in the Malu Formation. A large regional fault (Graben Fault) exists in the eastern flank of the main orebody, which is intersected by mine development. Reef and shear units cut the entire mine stratigraphical sequence generating frequent and pervasive jointing decreasing the overall rockmass strength making it amenable to caving (Woods et al. 2019). Intact rock strength is generally very high (greater than $200 \mathrm{MPa}$ ), except for the major ore units (around $80 \mathrm{MPa}$ ), with RMR values ranging from 50 to 60 (Woods et al. 2019). The Telfer underground operation consists of three separate and distinct mining areas (Figure 5b). The upper mine (M-Reefs) is focused on narrow vein reef extraction utilising longhole retreat stoping. The lower mine is made up of a mature sub level cave (SLC) operation and the Western Flanks open stoping area. Mining and maintenance activities are carried out by a mining contractor, with Newcrest providing technical services and management oversight. Currently mining is occurring to over $1,000 \mathrm{~m}$ below surface with shaft hoisting utilised to transport ore material from the lower mine. Ore from the upper mine is trucked to the surface for transportation to the processing plant. The current mine plan has the lower mine producing 2.9 Mtpa as the active footprint of the SLC reduces and the Western Flanks moves towards remnant mining activities (Kilkenny et al. 2019). 


\subsection{SPCE drawbell design}

The design brief for the drawbells and therefore drill and blast consisted of:

- To suit the El Teniente layout;

- Retain existing pillar dimensions at Cadia East;

- Use existing mining equipment available at Telfer; and

- Robust and repeatable design

In conjunction with the above, the decision was made to not apply current novel blasting technology to the Telfer scope. This decision was twofold; regulatory restriction relating to pre-charging and also demonstrating that the success could be achieved using conventional technology. The aim being to reduce complexity and identify improvement opportunities. The decision to utilise existing equipment primarily production drill rigs (conventional top hammer), impacted the final design. Due to the expected impact of drill deviation at hole lengths greater than $30 \mathrm{~m}$ and emulsion retention issues in long upholes, a decision was made to use $89 \mathrm{~mm}$ diameter holes instead of the $76 \mathrm{~mm}$ diameter holes used at Cadia East in the past for drawbell development, and to limit hole lengths to a maximum of $34 \mathrm{~m}$. This influenced blast design and therefore the size and geometry of the resultant Telfer trial SCPE drawbells.

At its highest The SCPE drawbell shape is 32.5 metres high and has a total volume of $12,220 \mathrm{~m}^{3}$. The volume is comprised of two parts; the drawbell cone is $\sim 5,700 \mathrm{~m}^{3}$, while the undercut is $\sim 6,500 \mathrm{~m}^{3}$. At its highest point the major apex is $27.5 \mathrm{~m}$ high and undercut $10.5 \mathrm{~m}$. Figure 6 illustrates the drawbell geometry trialled at Telfer.

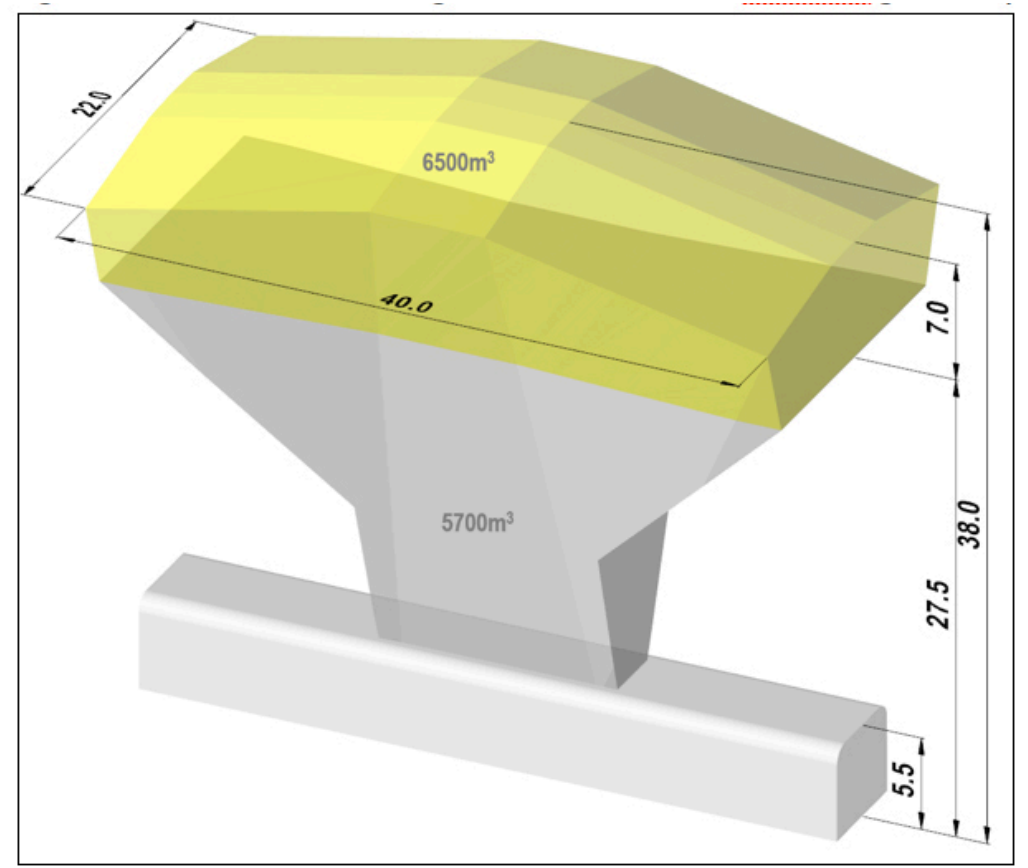

Figure 6 Drawbell geometry

The design in brief calls for an uphole raise (boxhole) to be established in the centre of the drawbell drive which provides initial relief. The drawbell is drilled in full and all holes surveyed before charging can begin. The drawbell is then opened in five separate blast events beginning with the slot as seen in Figure 7. 


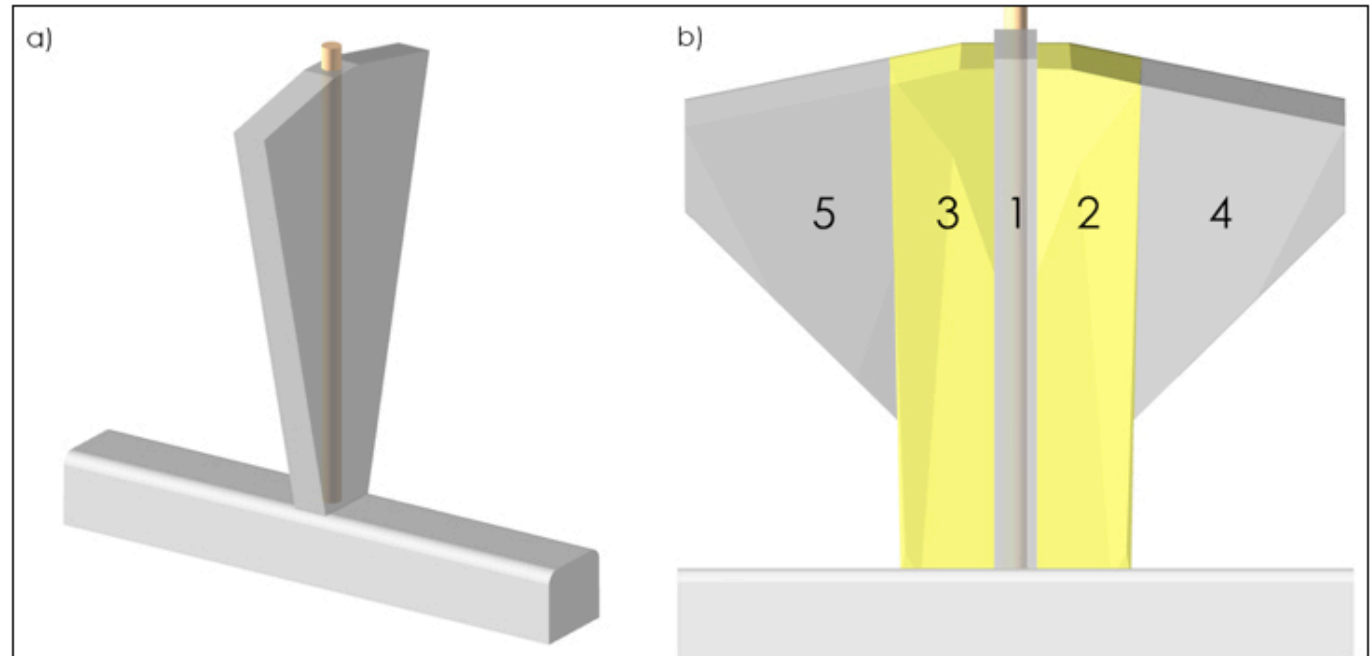

Figure 7 SCPE blasting stages (a) slot and (b) individual drawbell blasting stages

\subsection{Location and layout}

A $34 \mathrm{~m} \times 20 \mathrm{~m}$ El Teniente Layout was developed in Telfer's M-Reefs mining area. Suitability criteria for the trial location included minimal disruption to operations, minimal required development, quick access to multiple headings, and safe distance from critical infrastructure and the base of the active Main Dome open pit operation (see Figure 8a). Available drill hole data together with conditions observed in nearby excavations indicated appropriate quality rockmass with localised poorer conditions in the Reef that intersects the designed drawbells. A stability analysis of the final opened shape was performed concluding that the arched back would remain stable after the trial was completed. The total lateral development scope comprised of $420 \mathrm{~m}$ including stockpiles and a truck loading bay (see Figure 8b). Extraction drive profile was $5 \mathrm{~m}$ wide $\times 5 \mathrm{~m}$ high. Drawbell slot drilling required a central stripping of the drawbell drive to $6.3 \mathrm{~m}$ wide for a distance of $6 \mathrm{~m}$. Given that the geotechnical conditions of the trial location allowed for large profiles, a $6.3 \mathrm{~m}$ wide $\times 5.5 \mathrm{~m}$ high profile was applied to the entire drawbell drive to avoid stripping and provide enough height for the uphole raise machine. Reducing drive size is a focus for the Cadia East trial. Materials handling was via conventional loader and truck methodology, with two dedicated stockpiles being established as per Figure $8 \mathrm{~b}$. All material was trucked to a surface stockpile via the main decline.

a)

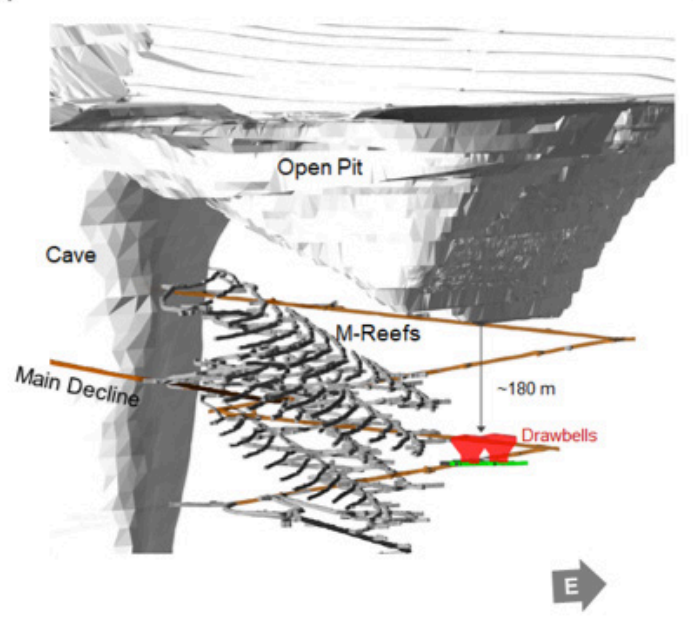

b)

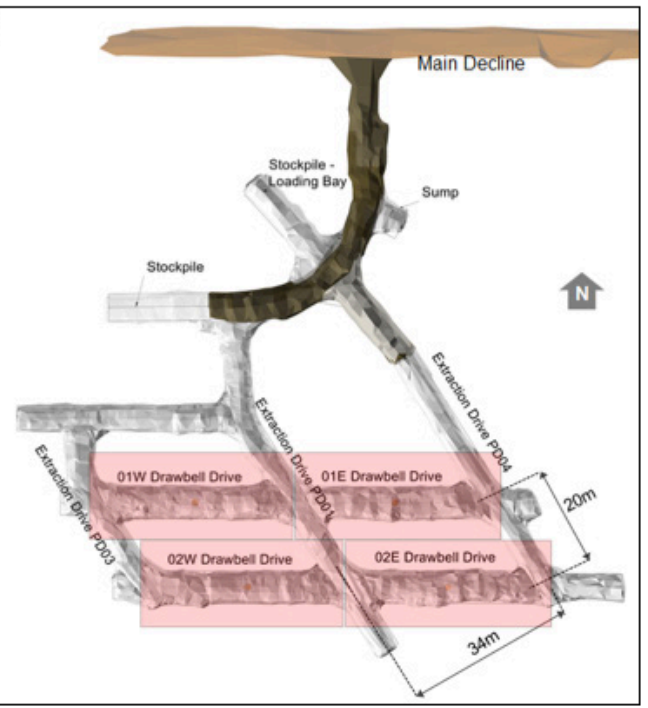

Figure 8 (a) Isometric view of trial location in the M-Reefs sector; (b) Plan view of trial layout 


\subsection{Overall sequence and geotechnical monitoring}

During the design stage a comprehensive geotechnical review was conducted focussing on the stability of the SPCE excavation, both during construction and at completion. Figure 9a illustrates the drawbell opening sequence which was guided by both geotechnical and operational considerations. The main drivers were:

- Open end-to-end drawbells first in order to delay the wider span being opened, and to simulate the likely sequence in a production application of SPCE

- Open south drawbells before north drawbells in order to retreat towards the access.

- Minimise physical interaction (thus improving safety) between activities to enable continuous drilling once charging and blasting activities commenced

A geotechnical monitoring program was installed to proactively assess the condition of critical pillars during and after the trial. This included the following:

- Major apex pillar monitoring - qualitative blast hole camera surveys and smart cables were installed in the major apex pillars prior to firing (Figure 9b)

- Crown Pillar monitoring - two 130 m long diamond drill holes were drilled from the I30 Decline to assess for crown pillar failure. One was monitored using Multi Point Borehole Extensometer (MPBX) cables while the other was left open to complete borehole camera surveys as required. (see Figure 9b)

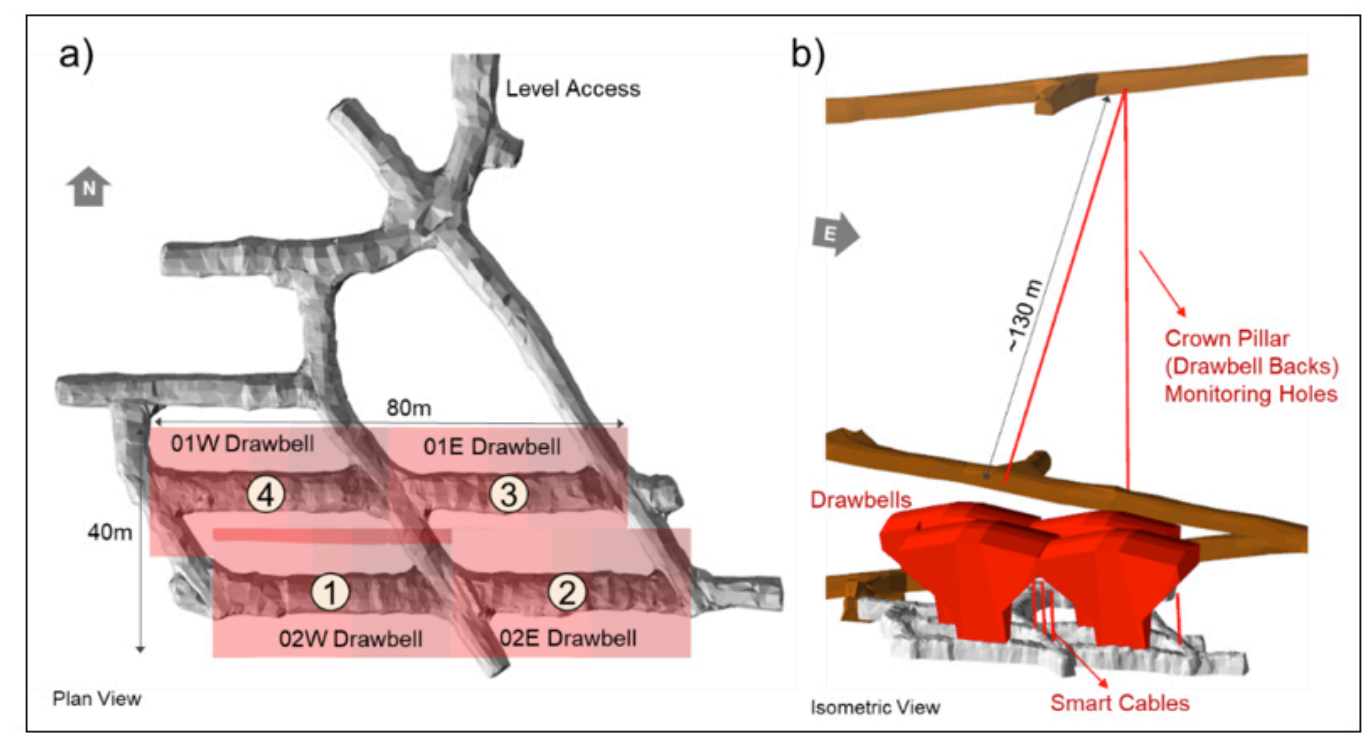

Figure 9 (a) Plan view showing drawbell opening sequence; (b) Isometric view showing geotechnical monitoring instrumentation

\subsection{Project execution}

Physical works commenced at Telfer in January 2019 and were completed in March 2020 - a duration of 15 months. The project was integrated into the existing Telfer mine systems and forecasts. In conjunction with the Telfer UG technical services, operations and geotechnical teams, members of the SPCE project team were dedicated to manage and coordinate various components of the trial. This was to ensure; a high level of safety was maintained, QA/QC was completed, due process was followed, and key data was collected. As a summary (as illustrated in Figure 10 and outlined over the subsequent points), the Telfer execution followed the following sequence: 


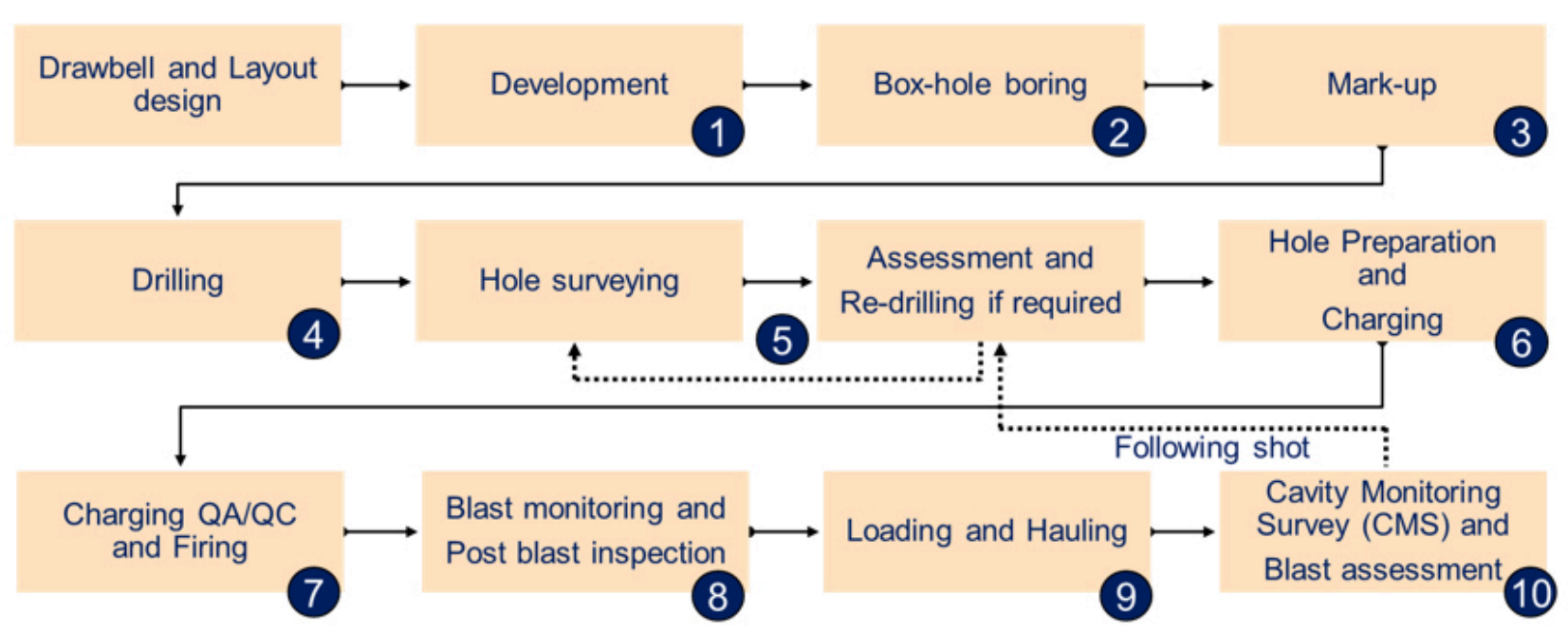

Figure 10 SPCE Telfer trial implementation methodology

1. Development mining activities were carried out by the incumbent mining contractor utilising twin boom development drills. Ground support varied depending on drive profile, however at a minimum fibrecrete and mesh were installed with bolts of dynamic capacity

2. A specialist raiseboring contractor was mobilised to site to execute a scope of four (4) uphole raises. These were drilled in series after development was completed to allow concurrent activities in the footprint. Raise as-built shapes and bolt positions were picked-up to adjust the slot holes collars if required

3. Mark-up procedure included laser lines off-sets and hole collaring mark-up to minimise collaring error.

4. Drilling was executed by the mining contractor using a Sandvik DL421 rig with Minnovare's Production Optimiser ${ }^{\circledR}$ (Azi Aligner) tool with the objective to minimise collar alignment error.

5. A specialist provider (DHS Australia) was mobilised to conduct detailed drill hole surveys. A survey was performed for every hole using an IsGyro ${ }^{\circledR}$ mounted on heavy duty poly pipe (see Figure 11a). Surveying was required to understand the deviation and impact it may have, as well as allowing as-drilled holes to be assessed for any remedial re-drills for each shot. Re-drilled holes were also surveyed and assessed before issuing the charge and timing plan for the shot

6. After hole preparation, blastholes were charged with Dyno Nobel Titan 7000SX ${ }^{\circledR}$ bulk emulsion and initiated with SmartShot ${ }^{\circledR}$ electronic detonators. A combination of red caps, MTi's blastbags ${ }^{\circledR}$ and blastballs ${ }^{\circledR}$ were used for charge retention and to minimise slumping. Selfinflating Blastbags ${ }^{\circledR}$ were cooled on ice to slow down the inflation process and reach up to $15 \mathrm{~m}$ up the hole where required. Inflatable Blastballs ${ }^{\circledR}$ and Blastbags ${ }^{\circledR}$ were used to reach higher collaring heights as they could be inflated after being positioned inside the hole (Figure 11b).

7. Charging and timing QA/QC was conducted by the Newcrest technical team and Dyno Nobel supervisors prior to firing each shot in order to detect deviation to the plan and amend as appropriate. Checks included detonator timing, response and leakage, explosive retention (observable slumping) and actual charge weights (see Figure 11c).

8. During the blast events, three uniaxial blast monitors were installed in the footprint to measure vibrations caused by the blast to record the overall behaviour. After the blast and prior to loading, visual inspections were conducted in order to assess blast ejection, fragmentation as well as the level of damage inflicted on drawpoints and pillars (Figure 12). 
9. All material movement was carried out using conventional truck and loader practices, utilising the contractor's Sandvik LH621 loaders and TH663 (60t) articulated trucks. A dedicated waste pad was set up near the main portal to minimise tram distance.

10. Shots were emptied and the cavity surveyed (CMS) to assess blast outcome. Drone surveying (LiDAR) was performed to scan the as-built shapes of the shots with low visibility for the conventional CMS (see Figure 13).

For each fired shot, all data was collected, analysed and, if necessary, specific instructions or re-designs were issued before proceeding to fire the next shot. This was to ensure learning and continuous improvements were being applied.

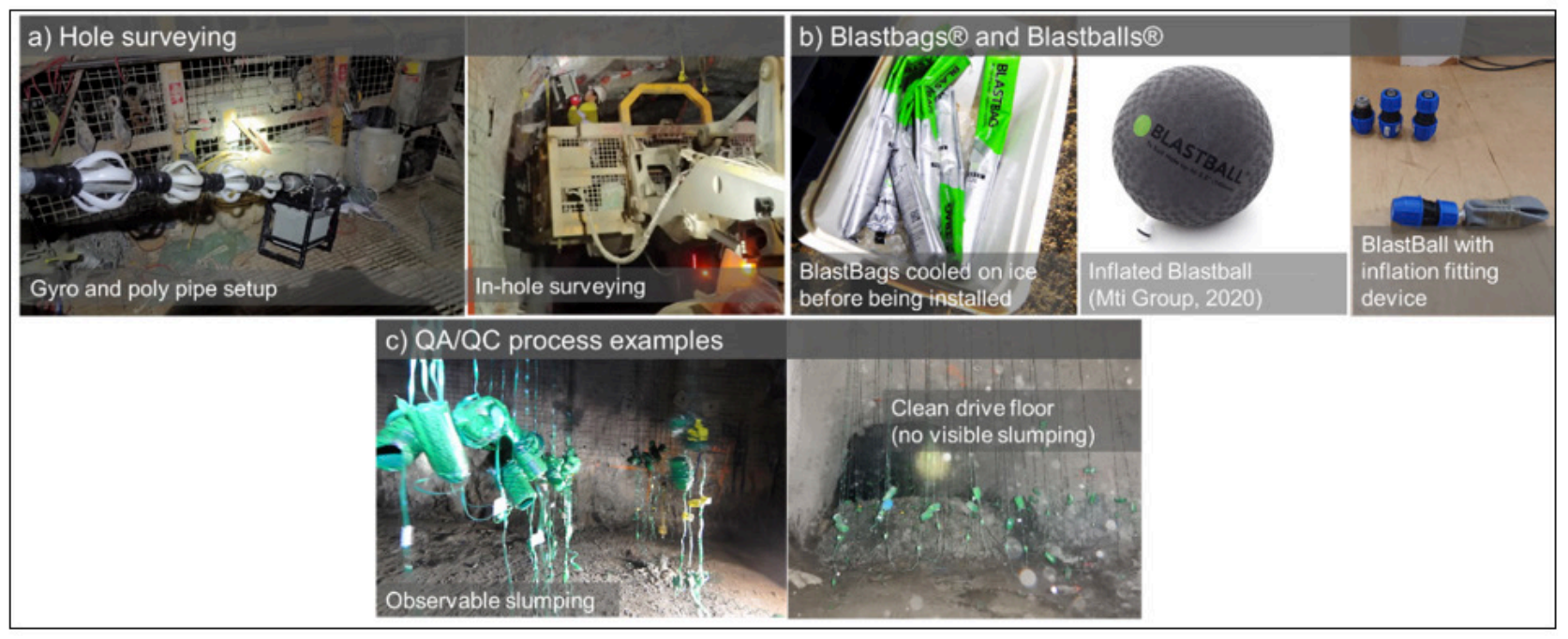

Figure 11 Examples of hole surveying, blastbags and blastballs, and QA/QC processes

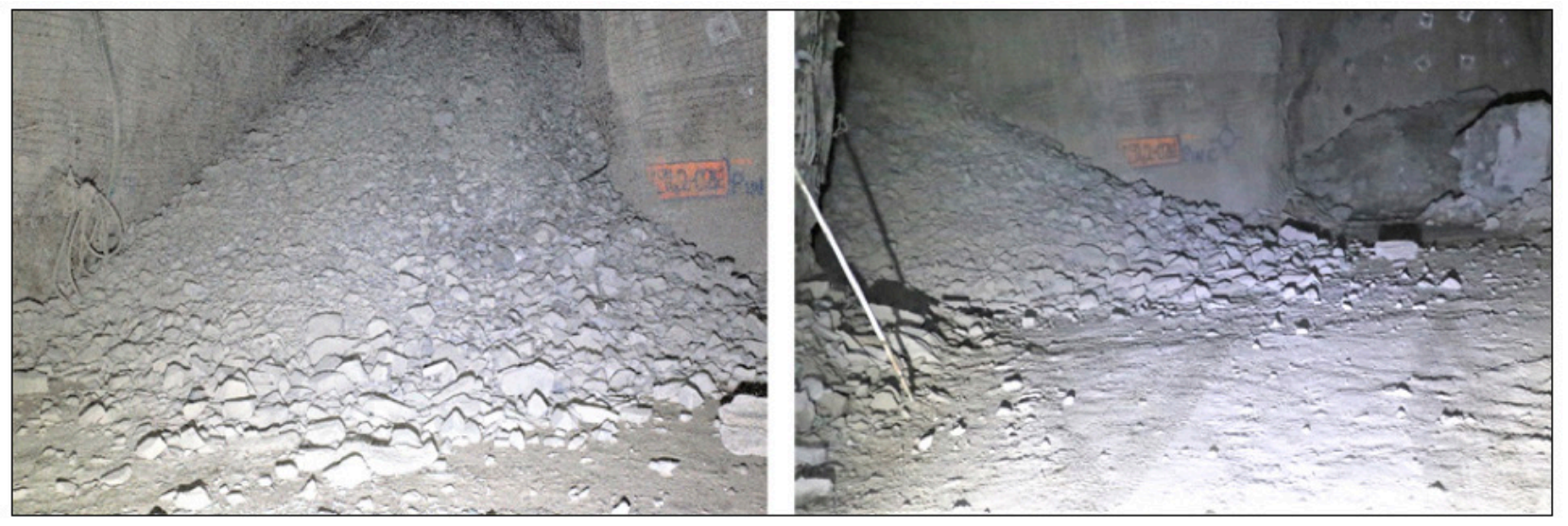

Figure 12 Example of post blast inspection showing blast ejection and fragmentation for 02E Slot shot

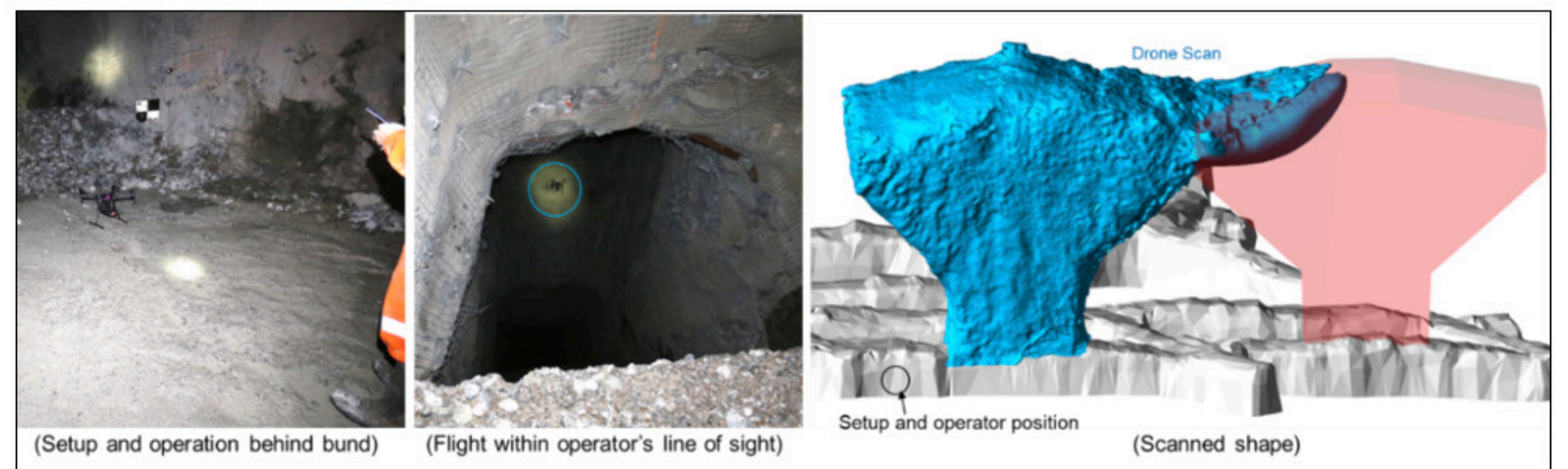

Figure 13 Example of drone scan in 02W drawbell 


\section{$5 \quad$ Telfer trial results and key learnings}

The Telfer trial was completed in March 2020 and, as shown in Figure 14, full connectivity was achieved between the drawbells, both across the major and minor apex pillars. Undercut planned height was also achieved across all four drawbells. Most importantly, this was all completed without a single safety incident.

The measured overall underbreak was 9 percent, mainly concentrated in the drawbell backs, however this did not compromise the full achievement of the planned undercut height and drawbell connectivity.

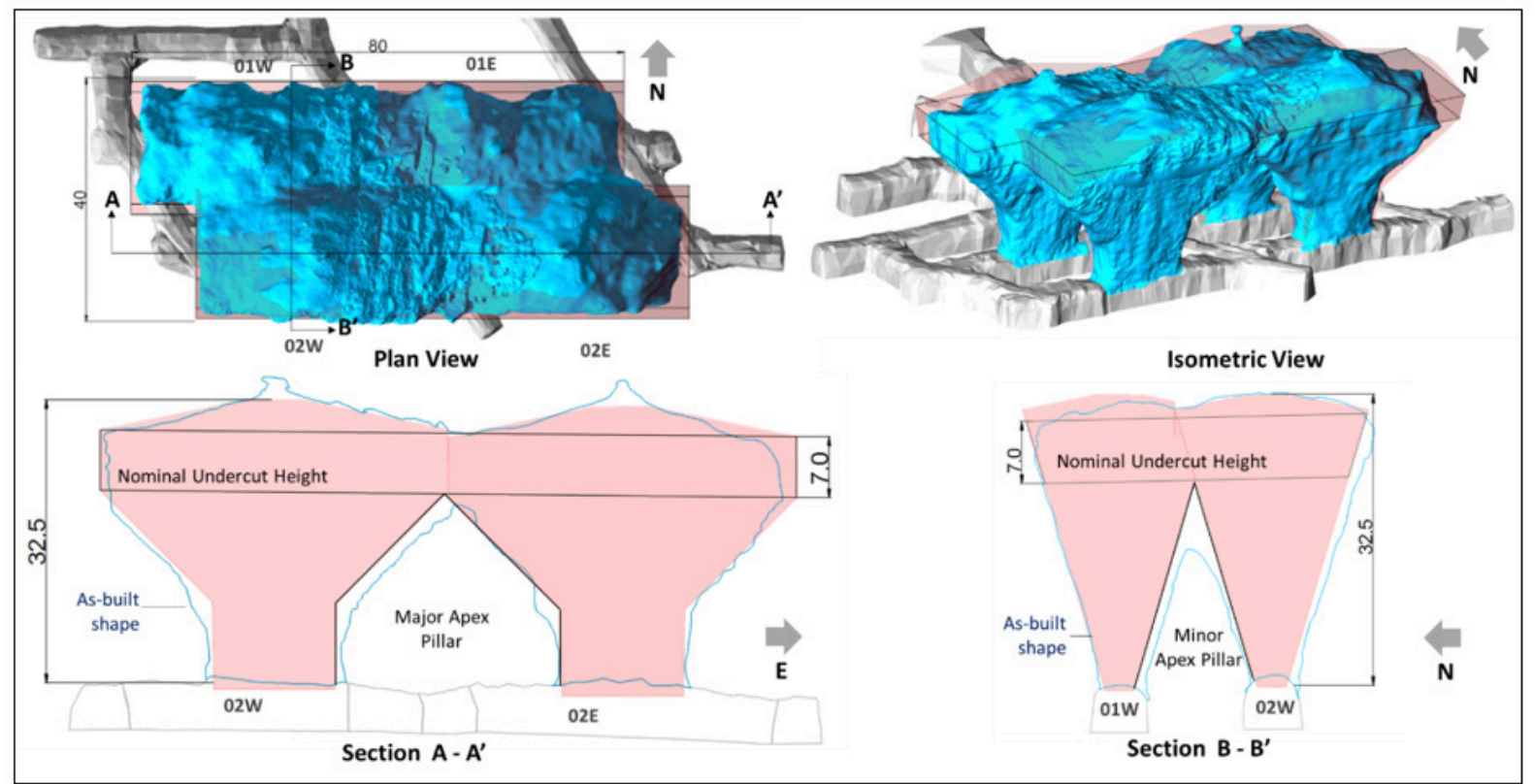

Figure 14 Achieved drawbell shapes, undercut height and connectivity across major and minor apex pillars (measures in metres)

Several key learnings are evident on completion of the Telfer trial. In order of execution sequence these, along with remedial recommendations are:

Development quality:

- Drawbell drives were mined with an inconsistent profile including excessive overbreak in some areas. This caused difficulty in collaring and drilling holes as per design. Blast damage inflicted during development contributes to brow overbreak and premature erosion. Smooth blasting techniques and stringent quality control shall be incorporated in the next trial to be conducted at Cadia East mine.

\section{Drilling accuracy:}

- Based on the comprehensive survey data set, overall average toe deviation was approximately $3 \%$ ( 1.0 $\mathrm{m}$ for a typical $30 \mathrm{~m}$ hole), with some toes deviating up to $9.5 \%$. Compounding this, a high degree of variability in the deviation direction caused several holes to cross over rings or leave large gaps. Remedial actions including re-drilling (overall 5\% re-drilling rate) and hole grouting were required to improve the explosive distribution within the blast. Enhanced drilling accuracy is required for the following trial and further SPCE implementation. This can be achieved by using In The Hole (ITH) or Wassara style drilling equipment. 
Drawbell Overbreak:

- Some overbreak was observed at the intermediate and final brows and to a lesser degree within the pillars. This has been attributed to the structural fabric in the trial area in conjunction with the blasting damage from development, as well as explosive retention techniques.

Pillar Integrity:

- The decision to not use a solid stemming product for the pillar defining blastholes meant that the pillars suffered varying degrees of blast damage. This issue will be addressed in the next trial in Cadia East.

\section{Path forward - Considerations for the Cadia East Trial}

Building on the proof of concept and lessons learned from the Telfer trial, the Cadia East trial will aim to further test the SPCE method in the Cadia East rockmass environment. The proposed trial will assess and if viable include the following;

- The application of smooth blasting techniques for the drawbell drives and extraction level.

- A refined drill and blast drawbell design aimed at minimising damage to drawpoints and pillars, considering smaller drive profiles than Telfer trial.

- The use of more accurate drilling equipment, such as In The Hole (ITH) drilling rigs to achieve a higher drawbells.

- Wireless electronic detonators.

- Improved inhole explosive retention techniques.

- Pillar integrity monitoring designed to deliver the key data required to model the Cadia East rockmass response to a future large-scale implementation of the method.

- Alternative shape and connectivity confirmation methods such as C-ALS®, TDR (Time Domain Reflectrometry) and Smart Markers to verify critical connectivity and successful blast after every shot without the need to empty the drawbell.

\section{Conclusions}

The Single Pass Cave Establishment Method (Undercutless Caving) is envisaged to constitute a significant step change for the underground mass mining industry. It aims to provide a safer working environment while reducing cave establishment cost and duration via opening drawbells and undercutting the orebody from a single level, eliminating the undercut level. In order to successfully validate and implement the SPCE method, a project consisting of a study and two practical trials is underway within Newcrest.

Successful results from the trial at Telfer have been achieved, with complete undercut and connectivity achieved across the four drawbell footprint. This is an industry first where a series of drawbells and undercut have been established from a single level with no aid from a void above (undercut or other development). The drawbells, pillars and undercut height were developed to design specification. This milestone represents a significant step forward in drawbell establishment for the industry.

Experience and lessons learned from the first trial are being transferred to the second trial in Cadia East. This trial will address key issues encountered; i.e. development quality, drilling accuracy and brow and pillar protection in the Cadia East rockmass environment. 


\section{Acknowledgement}

The authors would like to thank Newcrest Mining Limited for allowing the publication of this paper. We would also like to acknowledge all those involved in the Telfer Trial execution, especially the Telfer UG technical services, operations and geotechnical teams, along with all business partners who contributed along the journey.

\section{References}

Barraza, M \& Crorkan, P 2000, 'Esmeralda Mine Exploitation Project', in G Chitombo (ed.), Proceedings of MassMin 2000 , Australian Institute of Mining and Metallurgy, Melbourne, Australia, pp. 267-278.

Butcher, R 2000, 'Block Cave Undercutting - Aims, Strategies, Methods and Management', in G Chitombo (ed.), Proceedings of MassMin 2000, Australian Institute of Mining and Metallurgy, Melbourne, Australia, pp. 405-441.

Codelco 2018, 'Evolution of Mining Methods at El Teniente Mine', presentation for 2018 Caving Knowledge Workshop, Phoenix, USA.

Cuello, D \& Newcombe, G 2018, 'Key geotechnical knowledge and practical mine planning guidelines in deep, high-stress, hard rock conditions for block and panel cave mining', in Y Potvin \& J Jakubec (eds), Proceedings of the Fourth International Symposium on Block and Sublevel Caving, Australian Centre for Geomechanics, Perth, pp. 17-36

Dunstan, G and Popa, L 2012, 'Innovative Cave Establishment Practices at Ridgeway Deeps', Proceedings of MassMin 2012, Canadian Institute of Mining, Metallurgy and Petroleum, Sudbury, Canada.

Dunstan, G 2016, 'The truth is stranger than fiction - the story of Ridgeway Gold Mine', Proceedings of MassMin2016, Australasian Institute of Mining and Metallurgy, Sydney, pp. 19-30.

Flores, G 2019, 'Major hazards associated with cave mining: are they manageable?', in J Wesseloo (ed.), Proceedings of the First International Conference on Mining Geomechanical Risk, Australian Centre for Geomechanics, Perth, pp. 31-46.

Flores, G 2014, 'Future challenges and why cave mining must change', in R Castro (ed.), Proceedings of Caving 2014, third International Symposium on Block and Sublevel Caving, Universidad de Chile, Santiago, Chile, pp. 23-52.

Kilkenny, D, Kline, P \& Nardini, K 2019 "Collaboration and Change Management, keys to successful automation implementation" Submitted for the 2020 AusIMM Underground Operators Conference.

Laubscher, D, Guest, A, Jakubec, J \& Chitombo, G 2017, 'Guidelines on Caving Mining Methods - the underlying concepts'. Chapter 8. W.H. Bryan Mining and Geology Research Centre, Brisbane, Australia, pp. 103 - 109.Macquarie Research 2016, 'Metals and Mining. A chip off the new block GLOBAL. Evaluating the risks and rewards of the future block cave. Inside', Macquarie Group. [21 November 2016].

Manca, L \& Flores, G 2013, 'Modern Planning Practices for Cave Mining', Proceedings of MinePlanning 2013, 3rd International Seminar on Mine Planning, GECAMIN, Santiago, Chapter 3.

Pierola, M, Adamson, W \& Diaz, M 2006, 'Design, Implementation and Control of Large Scale Draw Bells (zanjas) in Panel Caving, Codelco Division El Teniente'. In proceedings of Fragblast-8. The 8th International Symposium on Rock Fragmentation by Blasting. Santiago, Chile, pp. $279-289$.

Rojas, E, Molina, R, Bonani, A, \& Constanzo, H 2000, 'The pre-undercut caving method at the El Teniente Mine, Codelco Chile', in G Chitombo (ed.), Proceedings of MassMin 2000, Australian Institute of Mining and Metallurgy, Melbourne, Australia, pp. 261-266.

Tawadrous, A \& Preece, D 2015, 'A novel blasting technique to create drawbells and eliminate the undercut level in block cave mining', in Proceedings 11th International Symposium on Rock Fragmentation by Blasting, The Australasian Institute of Mining and Metallurgy, Melbourne, Australia, pp 617-624.

Trueman, R, Pierce, M \& Wattimena, R 2002, 'Quantifying stresses and support requirements in the undercut and production level drifts of block and panel cave mines', International Journal of Rock Mechanics and Mining Sciences, Vol. 39, pp. $617-632$. 
Vergara, C, Rivera, N \& Music, A 2018, 'Drilling and Blasting in El Teniente Mine - Design and Operational Practices- Teniente Sub 6 case study" II Ibero-American Congress in Underground Mining and Open Pit. Castro, R. and Herazo, Y. (eds). Santiago, Chile, 13-15 June 2018. Presentation, in Spanish.

Woods, MJ, Fitch, S, Doolan, J \& Barnett, DS 2019, 'A case study: managing decline deformation in an active sublevel caving operation', in J Wesseloo (ed.), Proceedings of the First International Conference on Mining Geomechanical Risk, Australian Centre for Geomechanics, Perth, pp. 505-520 